Gabriela Sabatini Barros Sales Geografia, Literatura e Arte, v.2, n.2, p. 109-128, jul./dez.2020

Jeferson Rosa da Silva

DOI: 10.11606/issn.2594-9632.geoliterart.2020.168163

Maria Luiza Félix Marques Kede

Ana Claudia Ramos Sacramento

\title{
VIDAS SECAS DE GRACILIANO RAMOS: SUAS E OUTRAS PAISAGENS PELAS TINTAS NATURAIS DE SOLO ${ }^{1}$
}

\section{GRACILIANO RAMOS' VIDAS SECAS: ITS AND OTHER LANDSCAPES BY NATURAL SOIL PAINTS}

\section{VIDAS SECAS DE GRACILIANO RAMOS: SUS Y OTROS PAISAJES POR PINTURAS DE SUELO NATURALES}

\author{
Gabriela Sabatini Barros Sales ${ }^{2}$
}

Universidade do Estado do Rio de Janeiro, Rio de Janeiro, Brasil

Jeferson Rosa da Silva ${ }^{3}$

Universidade do Estado do Rio de Janeiro, Rio de Janeiro, Brasil

Maria Luiza Félix Marques Kede

Universidade do Estado do Rio de Janeiro, Rio de Janeiro, Brasil

Ana Claudia Ramos Sacramento 5

Universidade do Estado do Rio de Janeiro, Rio de Janeiro, Brasil

\begin{abstract}
Resumo: A oficina "Retratando o conceito de paisagem a partir da Geografia, da Literatura e de atividade prática com tinta natural" objetivou trabalhar as interpretações das imagens construídas com uso de tintas naturais de solo a partir do conceito de paisagem. Inspirando-se em pequenos trechos de Vidas Secas de Graciliano Ramos, o material desenvolvido foi produzido por estudantes do ensino fundamental e médio numa escola no município de São Gonçalo (RJ) por docentes e discentes do curso de Licenciatura em Geografia da UERJ-FFP. Os resultados mostram a percepção de como a forma interdisciplinar de ensinar amplia a capacidade de reflexão e construções de saberes tanto escolares quanto cotidiano do aluno.
\end{abstract}

Palavras-chave: Literatura, Geografia, Oficinas pedagógicas.

\footnotetext{
${ }^{1}$ Os autores agradecem ao CETREINA/UERJ, à FAPERJ e ao CNPq pelo apoio recebido.

${ }^{2}$ Graduanda em Geografia, Universidade do Estado do Rio de Janeiro, E-mail: sabatinibs@gmail.com ${ }^{3}$ Mestrando em Geografia, Universidade do Estado do Rio de Janeiro, E-mail: jefersonrosageo@gmail.com

${ }^{4}$ Professora adjunta do Departamento de Geografia da Universidade do Estado do Rio de Janeiro, Email: mluizakede@gmail.com

${ }^{5}$ Professora associada do Departamento de Geografia da Universidade do Estado do Rio de Janeiro, Email: anaclaudia.sacramento@hotmail.com
} 
Gabriela Sabatini Barros Sales Geografia, Literatura e Arte, v.2, n.2, p. 109-128, jul./dez.2020

Jeferson Rosa da Silva

DOI: 10.11606/issn.2594-9632.geoliterart.2020.168163

Maria Luiza Félix Marques Kede

Ana Claudia Ramos Sacramento

Abstract: The workshop "Portraying the concept of landscape from Geography, Literature and practical activity with natural paint" aimed to work on the interpretations of images constructed using natural soil paint, based on the landscape concept. Inspired by short excerpts from Graciliano Ramos's Vidas Secas, the developed material was produced by elementary and high school students in a school in the city of São Gonçalo (RJ), by teachers and students in Geography degree course of the UERJ-FFP. The results show the perception of how the interdisciplinary way of teaching expands the student's capacity for reflection and construction of knowledge, both school and everyday.

Keywords: Literature, Geography, Pedagogical workshop.

Resumen: El taller "Retratando el concepto de paisaje desde la Geografía, la Literatura y la actividad práctica con pintura natural" tenía como objetivo trabajar en las interpretaciones de imagenes construidas con el uso de pintura natural del suelo por el concepto de paisaje. Inspirado en pequeñas partes de Vidas Secas de Graciliano Ramos, el material desarrollado fue producido por estudiantes de primaria y secundaria en una escuela en la ciudad de São Gonçalo (RJ), por maestros y estudiantes del curso de grado en Geografía de la UERJ-FFP. Los resultados muestran la percepción de cómo la forma interdisciplinaria de enseñaza amplía la capacidad del alumno de reflexión y construcción del conocimiento, tanto escolares como el día a día.

Palabras clave: Literatura, Geografía, Taller pedagógico.

\section{INTRODUÇÃO}

Pensar as diferentes formas de ensinar Geografia possibilita organizar atividades de aprendizagem as quais rompem com as dinâmicas tradicionais de uma aula e, desta forma, tornando-as mais significativas para os estudantes. Para tanto, os conceitos e os conteúdos precisam ser desenvolvidos a partir de alguns elementos basilares - (a) Para que serve esse conteúdo e conceito? (b) Que tipo de proposta pedagógica será trabalhado? (c) Quais são as linguagens que possibilitam mediar o conhecimento? (d) Como serão as etapas para a organização e execução deste?

Tendo em vista a criação de atividades didáticas, as oficinas pedagógicas têm sido uma metodologia utilizada para elaborar diferentes conceitos e conteúdos geográficos para promover conhecimento dos estudantes de forma teórico-prática (SACRAMENTO, 2017). A maneira de como se lê o mundo depende de como se 
Gabriela Sabatini Barros Sales Geografia, Literatura e Arte, v.2, n.2, p. 109-128, jul./dez.2020

Jeferson Rosa da Silva

DOI: 10.11606/issn.2594-9632.geoliterart.2020.168163

Maria Luiza Félix Marques Kede

Ana Claudia Ramos Sacramento

aborda a Geografia e quais são seus elementos fundamentais para fomentar no estudante o interesse de recontextualizar aquilo que está sendo ensinado.

O ensino de Geografia possibilita compreender a leitura de mundo a partir de várias concepções teórico-metodológicas e pedagógicas, para que o estudante possa construir formas de interpretação da realidade. Castellar e Vilhena (2010) atentam-se para a importância da capacidade de raciocínio dos conhecimentos geográficos para se ter uma relação com a apropriação do significado do conceito a ser trabalhado. Segundo as autoras, o conceito carrega consigo um conjunto de elementos que estão para além daquilo que inicialmente o estudante imagina. Por isso, a necessidade de uma proposta didática que o possibilita entender e analisar o conceito.

O conceito de paisagem tem uma grande relevância para a ciência geográfica e para o ensino da Geografia. Segundo Santos (2014, p. 89), "a dimensão da paisagem é a dimensão da percepção que chega aos sentidos”. O olhar sobre a paisagem pode proporcionar o desenvolvimento de várias questões. Dentre elas, construir a ideia e percepção do seu sentido e significado. Para tanto, o uso da Literatura como uma linguagem, de acordo com Silva e Barbosa (2014) pode desenvolver a construção do conhecimento a qual requer envolvimento dos estudantes sobre o processo interdisciplinar na leitura e interpretação de uma realidade.

A Literatura é uma manifestação artística carregada de aspectos históricos, culturais e sociais, nela a realidade pode tomar vários significados a partir da visão do autor, de sua vivência, seus sentimentos e imaginário. As obras literárias carregam ideias, fatos e conhecimentos, através delas, os símbolos, os lugares, o tempo e o espaço são retratados pela subjetividade. Carvalho (2014) aponta que os textos literários se apresentam como um valioso material, sobretudo, por sua evocação da atmosfera dos lugares e do cotidiano social. Quando se recorre à obra literária, tornase possível resgatar contribuições com retratos de fragmentos do espaço em transformação, articulando vivências e experiências.

Desse modo, a articulação da Geografia com a Literatura promove a compreensão das dinâmicas sociais do mundo, podendo ampliar a capacidade de interpretação e pensamento crítico do leitor. Percebe-se a importância da Literatura 
Gabriela Sabatini Barros Sales Geografia, Literatura e Arte, v.2, n.2, p. 109-128, jul./dez.2020

Jeferson Rosa da Silva

DOI: 10.11606/issn.2594-9632.geoliterart.2020.168163

Maria Luiza Félix Marques Kede

Ana Claudia Ramos Sacramento

como um instrumento de construção do conhecimento e importante diálogo interdisciplinar para o processo de ensino-aprendizagem.

No caso deste trabalho, será apresentada uma atividade didática em formato de oficina intitulada "Retratando o conceito de paisagem, a partir da Geografia, da Literatura e de atividade prática com tinta natural". O objetivo é apresentar interpretações sobre o conceito de paisagem a partir de fragmentos extraídos da obra Vidas Secas de Graciliano Ramos por meio da tinta natural do solo por duas turmas da educação básica.

Esta proposta de atividade foi construída por docentes e discentes do curso de Licenciatura em Geografia, participantes do Laboratório de Geociências (LabGeo) da Universidade do Estado do Rio de Janeiro - Faculdade de Formação de Professores (UERJ-FFP). Este grupo de pesquisa recepciona no campus da universidade turmas do ensino fundamental e médio das escolas públicas do município de São Gonçalo e cidades vizinhas, a fim de aproximá-los do ambiente acadêmico e proporcionar um espaço de aprendizagem acerca de temáticas relacionadas à Geologia, a Climatologia e a Pedologia buscando trabalhar com os aspectos físico-naturais no ensino de Geografia. Atividades externas também são desenvolvidas pelos graduandos, possibilitando maior interação entre Universidade e Escola.

As oficinas escolares fazem parte do projeto de extensão de Geografia "Oficinas escolares em Geografia: diferentes ações didáticas" e das várias oficinas desse projeto existe uma com a temática de "Geografia, Literatura e Artes", que ocorre na unidade desde 2013 e tem como objetivo produzir atividades didáticas, oficinas, trabalhos de campo, capacitação para professores da rede pública e privada, entre outros.

A princípio serão retratadas as discussões que remetem a Geografia, a Literatura e a Arte como proposta de oficinas pedagógicas direcionadas para alunos de ensino fundamental e médio. Em seguida serão apresentados os conceitos de paisagens utilizados nesse trabalho e o livro Vidas Secas de Graciliano Ramos, no qual serão retirados pequenos trechos que retratam diferentes paisagens apresentadas na presente obra. Por fim, serão descritas e analisadas como as atividades de uma 
Gabriela Sabatini Barros Sales Geografia, Literatura e Arte, v.2, n.2, p. 109-128, jul./dez.2020

Jeferson Rosa da Silva

DOI: 10.11606/issn.2594-9632.geoliterart.2020.168163

Maria Luiza Félix Marques Kede

Ana Claudia Ramos Sacramento

oficina pedagógica envolvendo Geografia, Literatura e Arte podem ser conduzidas em sala de aula.

\section{OFICINAS PEDAGÓgICAS PARA PRODUÇÃO DO CONHECIMENTO INTERDISCIPLINAR: GEOGRAFIA E LITERATURA-PAISAGEM E SOLO}

A construção de oficinas pedagógicas para desenvolver as temáticas sobre o ensino de Geografia tem sido uma das metodologias trabalhadas nos últimos anos no projeto de extensão. Sendo assim, as oficinas visam, dentre inúmeros objetivos, a promoção da articulação entre teoria e prática. Em seu trabalho de pesquisa, Sacramento (2017) apresenta algumas formas de se organizar as oficinas com temas, conceitos e conteúdos distintos.

Para as autoras Paviani e Fontana (2009), a oficina como uma metodologia se torna uma maneira de construir o conhecimento, pois a questão central é a açãomovimento teórico-prático da aprendizagem, já que o estudante desenvolve coletivamente ou não uma determinada atividade. Desta maneira, ele, por meio da ação e reflexão, precisa construir formas para fazer as atividades práticas dentro das oficinas. As oficinas pedagógicas permitem trabalhar com diferentes métodos de ensino e buscar o trabalho interdisciplinar que dificilmente é desenvolvido nas aulas tradicionais.

Utilizar as oficinas e a Literatura em sala de aula além de tornar a aula mais dinâmica, convida os alunos a participarem desde a sua produção até o debate sobre as diferentes interpretações trazidas por eles. A interdisciplinaridade favorece o desenvolvimento de diferentes atividades educativas, de acordo com Silva Filho, Araújo e Silva (2019) ela pode ser tomada como uma gama de conhecimento que se permite aos aprendizes percorrer todos os quesitos que envolvem as especificidades de diferentes áreas.

A oficina a seguir aconteceu em 2018, tivera duas horas de duração e foi realizada em duas turmas: uma do $9^{\circ}$ ano do ensino fundamental e outra do $2^{\circ}$ ano do ensino médio do CIEP 439 - Luiz Gonzaga Júnior, localizado no município de São 
Gabriela Sabatini Barros Sales Geografia, Literatura e Arte, v.2, n.2, p. 109-128, jul./dez.2020

Jeferson Rosa da Silva

DOI: 10.11606/issn.2594-9632.geoliterart.2020.168163

Maria Luiza Félix Marques Kede

Ana Claudia Ramos Sacramento

Gonçalo (RJ). Esta ocorreu em momentos distintos buscando por meio das interpretações dos fragmentos da obra Vidas Secas pensar as paisagens a partir das representações dos estudantes com tintas naturais de solo. A oficina foi dividida em quatro etapas.

$\mathrm{Na}$ primeira etapa, foi apresentado o conceito de paisagem aos alunos por meio de questionamentos e exposição de algumas definições de autores sobre o conceito em estudo. Esta reflexão se fundamentou principalmente nas contribuições de Sauer (1998 [1925]) e de Santos (2014).

Santos (2014) disserta que "a dimensão da paisagem é a dimensão da percepção" (p.89), daquilo que é captado pelos sentidos, compreendendo que a paisagem é formada não apenas por volumes, mas por cores, movimentos, odores, sons. A paisagem, deste modo, possui diferentes formas, conteúdos e estruturas distribuídas em diferentes espaços, os quais têm arranjos paisagísticos com suas cores e movimentos; e, por essa razão, suas características são distintas.

Já Sauer (1998 [1925]) destaca que a Geografia se baseia na união dos elementos físicos e culturais da paisagem. O autor considera que o conteúdo da paisagem é encontrado nas qualidades físicas de uma dada área que são importantes para uso humano, de modo que a paisagem reúne fatos do substrato físico e fatos da cultura humana. Para Sauer, a paisagem é uma cena impregnada de significados (CORRÊA, 2014).

$\mathrm{Na}$ segunda etapa, foi apresentado o livro Vidas Secas de autoria do Graciliano Ramos publicado originalmente em 1938. Foram lidos alguns trechos previamente selecionados que retratam variadas paisagens, enquanto conta a história de uma família itinerante que caminha fugindo da aridez da caatinga. Contudo, em alguns momentos, paisagens urbanas também são retratadas ao longo do enredo. Um pequeno resumo contendo os personagens, o ponto central da história e a organização do romance foi entregue aos diferentes grupos durante a oficina.

Além de uma narrativa sobre a pobreza e as dificuldades da vida dos retirantes no sertão nordestino, o autor aponta o contexto de desigualdade social. Desse modo, compreende-se que a obra Vidas Secas permite o desenvolvimento de inúmeras abordagens. Botoso (2013), por exemplo, discute os embates entre os opressores e 
Gabriela Sabatini Barros Sales Geografia, Literatura e Arte, v.2, n.2, p. 109-128, jul./dez.2020

Jeferson Rosa da Silva

DOI: 10.11606/issn.2594-9632.geoliterart.2020.168163

Maria Luiza Félix Marques Kede

Ana Claudia Ramos Sacramento

oprimidos e a perpetuação da condição de exploração dos mais pobres em relação aos que detém o poder econômico. Ressalta-se, no entanto, que o presente trabalho não se debruça sobre esta discussão, por conta da delimitação apresentada na oficina em questão.

A Literatura como uma ciência e como uma linguagem permite dialogar com outra maneira de interpretar o mundo, a partir de diferentes formas, características e expressões que cada concepção literária carrega de seus autores. O drama vivido pelos personagens da obra contribui para pensar as condições e relações sociais e as diferenças regionais do clima. Este envolvimento do estudante e a leitura podem oferecer informações captadas, organizadas e trabalhadas com significados diversos para cada um, uma vez que parte do conhecimento são os sentidos sensoriais que a recebe e a outra, é transmitida por meio das vivências ao logo das experiências da vida (MELO; LIMA 2018).

Ao relacionar Literatura e Geografia, Lima (2000) destaca que muitas obras no campo literário estão entranhadas do caráter geográfico. A autora considera que isto pode ser observado por meio dos estilos de vida retratados, das características socioculturais, das estruturas econômicas e agrárias, da diversificação do meio físico do país, dentre outros. Neste contexto, ambas dialogam para pensar, a partir de Vidas Secas, diferentes paisagens e como as pessoas vivem nestes arranjos paisagísticos que têm características e formas únicas.

O conceito de paisagem comumente apresentado aos alunos do ensino fundamental e médio é trabalhado a partir daquilo que pode ser observado, entretanto ela não é apenas uma representação através de imagens. A leitura a partir da Literatura ajuda a compreendê-la além de somente olhar pela janela da sala, permite senti-la e imaginá-la. "A leitura detalhada do texto é, para a Geografia, a própria paisagem em suas expressões. Assim, o desafio está em formular caminhos e metodologias que abranjam as significações do visível e dizível através de artefatos e discursos expressos na paisagem" (SALES, 2016, p. 57). A abordagem interdisciplinar favorece o diálogo entre ambas sem descaracterizar suas especificidades de pensar a interpretação e análise da paisagem. 
Gabriela Sabatini Barros Sales Geografia, Literatura e Arte, v.2, n.2, p. 109-128, jul./dez.2020

Jeferson Rosa da Silva

DOI: 10.11606/issn.2594-9632.geoliterart.2020.168163

Maria Luiza Félix Marques Kede

Ana Claudia Ramos Sacramento

\begin{abstract}
O processo ensino-aprendizagem a partir da Geografia e da Literatura permite a edificação de uma interdisciplinaridade contribuinte para que os alunos tenham ampla compreensão das relações sociais, históricas e geográficas, também se soma a ampliação da capacidade crítica a partir de outra linguagem, as categorias da representação geográfica (MOREIRA, 1987) em consórcio com a literatura permitem a ampliação da compreensão do espaço cotidiano pelos alunos (SILVA; BARBOSA, 2014, p. 83).
\end{abstract}

Após a leitura, foi proposto um pequeno debate acerca do tema "Literatura e Geografia" e postas algumas questões tais como: (i) se os alunos conheciam o livro e se já tinham lido, (ii) se tinham visto alguma das paisagens retratadas, (iii) o que pensavam em relação às paisagens, dentre outras. Esta discussão acerca do trabalho foi necessária para o desenvolvimento e aprofundamento dos conhecimentos geográficos, a partir dos conhecimentos prévios dos estudantes acerca do conceito de paisagem.

$\mathrm{Na}$ terceira etapa, os alunos foram separados em grupos para a preparação das tintas de solo. Carvalho et al (2009) mostra em seu projeto as Cores de Tinta, diferentes propostas de uso de solo para produção de tintas naturais para a tintura de casas. Por meio desse projeto é possível compreender como desenvolver materiais que possam ser um diferencial. Segundo Carneiro (2015), o solo já foi muito utilizado para pintura desde a pré-história sendo a técnica denominada "barreado" usada no meio rural brasileiro.

Para esta etapa da oficina, os grupos tiveram acesso a cinco amostras de solo com cores diferenciadas que foram cedidas pelo LabGeo-UERJ-FFP. Tais amostras foram coletadas em diferentes áreas do município de São Gonçalo. A seguir, apresentou-se brevemente para as turmas algumas características sobre as amostras de solo, como local de coleta, cor, textura e presença de matéria orgânica.

Nesse momento a origem e a diversidade dos solos e suas diferentes características foram explicadas, por exemplo, como os solos podem ser avermelhados, amarelados, alaranjados, ter cores mais claras ou mais escuras, como podem ser argilosos, arenosos ou de outras texturas, como também podem ser rasos ou profundos, dentre outras características, de acordo com os fatores e os processos presentes na sua formação. 
Gabriela Sabatini Barros Sales Geografia, Literatura e Arte, v.2, n.2, p. 109-128, jul./dez.2020

Jeferson Rosa da Silva

DOI: 10.11606/issn.2594-9632.geoliterart.2020.168163

Maria Luiza Félix Marques Kede

Ana Claudia Ramos Sacramento

Para a preparação das tintas naturais, foram utilizadas as amostras de solo citadas, acondicionadas em copos plásticos com aproximadamente $30 \mathrm{~g}$ de solo. Em seguida, foram adicionados $40 \mathrm{ml}$ de água e $10 \mathrm{ml}$ de cola em cada copo, sendo misturadas até atingirem uma coloração homogênea. A partir disso foi proposta a feitura de uma representação de alguma paisagem relacionada ou não àquelas que foram mencionadas em Vidas Secas, podendo utilizar cartolinas, pincéis e as tintas de solo, não esquecendo de sugerir um título ao trabalho.

$\mathrm{Na}$ quarta etapa foi solicitado que cada grupo apresentasse seu trabalho, explicando a paisagem representada através da pintura e justificasse a escolha do título. Este momento foi importante para construção de ideias acerca da leitura da paisagem e a interpretação das práticas socioespaciais, bem como para a desconstrução de estereótipos difundidos pelo senso comum acerca das paisagens apresentadas nos trechos.

\section{PAISAGENS: AS IMAGENS RETRATADAS POR MEIO DE VIDAS SECAS E DE SEUS LUGARES DE VIVÊNCIAS}

O ensino da Geografia busca como já mencionado promover a análise espacial em diferentes escalas através de um conjunto de fontes, fenômenos e fatores determinados pelo meio social e físico-natural os quais ganham formas e que são usadas para um determinado fim. Este ensino possibilita a compreensão do desenvolvimento e da organização espacial, contribui para a reflexão sobre as relações de poder presentes nesse processo, incentivando um raciocínio mais crítico em relação à construção e às múltiplas transformações espaciais nas paisagens. Estas são muito importantes para o estudante analisar a paisagem em suas diferentes formas e funções dentro do espaço geográfico, uma vez que a escala do vivido e do nacional se completam ou não.

O mundo é pensado ou concebido, a partir de conceitos conforme aponta Castellar e Vilhena (2010), Sacramento (2014) os quais possibilitam aos estudantes compreender os objetos e fenômenos e suas diferentes dinâmicas e arranjos. Estudar o 
Gabriela Sabatini Barros Sales Geografia, Literatura e Arte, v.2, n.2, p. 109-128, jul./dez.2020

Jeferson Rosa da Silva

DOI: 10.11606/issn.2594-9632.geoliterart.2020.168163

Maria Luiza Félix Marques Kede

Ana Claudia Ramos Sacramento

conceito é construir a ideia de um conjunto de saberes mobilizadores na interpretação e análise de formas e sentidos.

\begin{abstract}
A formação do conceito tem como objetivo conceituar um fenômeno, sendo assim, é necessário centrar atenção em suas características (analisar, descrever sua totalidade concreta) a fim de destacar seus traços fundamentais, abstraindo-os do conjunto, em seguida, misturar (sintetizar) esses atributos mais importantes e simbolizá-lo com uma palavra (SACRAMENTO, 2014, p. 184).
\end{abstract}

Sendo assim, ao tratar a discussão do conceito de paisagem precisa-se entender o seu fenômeno e como se organiza no espaço. Desta forma, na primeira etapa, fora abordado o conceito de paisagem comumente trabalhado na Geografia escolar. De acordo com Sauer (1998[1925]), as paisagens podem ser divididas entre paisagens naturais e culturais. As naturais referem-se às paisagens não transformadas pela ação antrópica e as culturais são aquelas que já foram alteradas, a partir do esforço humano. O autor aponta o clima como um elemento-chave na morfologia da paisagem natural. Por sua vez, as formas da paisagem cultural, segundo o autor, são produzidas pelo homem.

Os conceitos de paisagem natural e paisagem cultural eram, de certo modo, conhecidos pelos estudantes. Eles associaram as paisagens formadas pelos biomas como naturais e de maneira geral as paisagens culturais foram associadas aos ambientes urbanos. A partir dessas colocações, os conceitos foram sendo aprofundados e outros exemplos dados, trazendo ao debate o entendimento de que em muitos casos as paisagens se inter-relacionam no espaço. Santos (2014) reforça que a paisagem é heterogênea e que em seu conjunto há frações de formas naturais e artificiais. Sauer (1998 [1925]) e Santos (2014) concordam que as paisagens naturais praticamente não existem mais. Ainda para Santos (2014) mesmo que um lugar não esteja sendo tocado fisicamente pela ação humana, existe uma intenção política, econômica para a não intervenção direta. Sendo assim, o autor compreende que tudo está cercado pelo interesse da história, sendo, portanto, social.

Em sala de aula foi possível constatar a materialização dessas ideias no local onde a escola está situada. Os alunos foram chamados a se aproximarem da janela e 
Gabriela Sabatini Barros Sales Geografia, Literatura e Arte, v.2, n.2, p. 109-128, jul./dez.2020 Jeferson Rosa da Silva

DOI: 10.11606/issn.2594-9632.geoliterart.2020.168163

Maria Luiza Félix Marques Kede

Ana Claudia Ramos Sacramento

observarem a paisagem, foram estimulados a refletir sobre as transformações decorrentes da ação antrópica. Silva e Barbosa (2014) chamam a atenção para o desenvolvimento do hábito de "se olhar pela janela" no aluno, para que no seu cotidiano possa analisar e, assim, perceber as modificações que ocorrem na paisagem ao seu redor ao longo do tempo.

Durante o desenvolvimento da atividade, a observação dos alunos pela janela sobre a paisagem ao redor da escola fez com que constatassem expressivas transformações, devido à presença de materiais e máquinas utilizadas em obras promovidas pelo governo do Estado do Rio do Janeiro na construção de uma Estação de Tratamento de Esgoto (ETE) que visa diminuir o despejo de esgoto in natura na Baía de Guanabara (Jornal Extra, 2014). Após a observação da paisagem foram apresentadas imagens locais registradas antes e após o início das obras (Figura 1).

Figura 1 - Imagem de satélite do entorno do CIEP 439 - Luiz Gonzaga Júnior (A) em 2003 e (B) 2019.

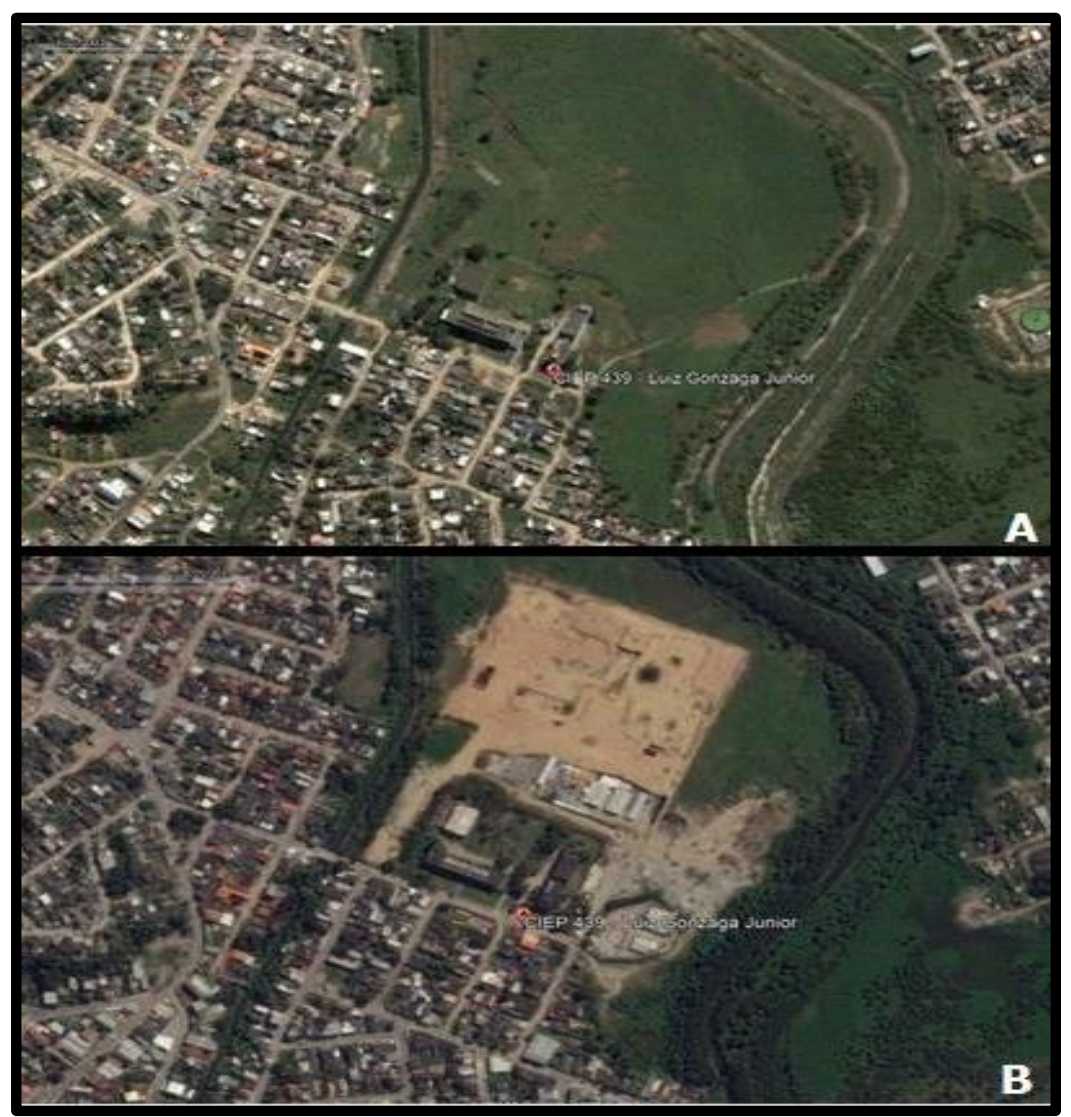

Fonte: Google Earth. 
Gabriela Sabatini Barros Sales Geografia, Literatura e Arte, v.2, n.2, p. 109-128, jul./dez.2020

Jeferson Rosa da Silva

DOI: 10.11606/issn.2594-9632.geoliterart.2020.168163

Maria Luiza Félix Marques Kede

Ana Claudia Ramos Sacramento

$\mathrm{Na}$ segunda etapa, foi apresentado um resumo do romance Vidas Secas de

Graciliano Ramos. Depois, foram lidos trechos que retratam algumas paisagens

(Figura 2), destacam-se alguns deles a seguir:

[...] Na planície avermelhada os juazeiros alargavam duas manchas verdes. Os infelizes tinham caminhado o dia inteiro, estavam cansados e famintos. Ordinariamente andavam pouco, mas como haviam repousado bastante na areia do rio seco, a viagem progredira bem três léguas. Fazia horas que procuravam uma sombra. A folhagem dos juazeiros apareceu longe, através dos galhos pelados da catinga rala (p. 3).

[...] A caatinga estendia-se, de um vermelho indeciso salpicado de manchas brancas que eram ossadas. $\mathrm{O}$ voo negro dos urubus fazia círculos altos em redor de bichos moribundos (p. 3). [...] Alcançou o pátio, enxergou a casa baixa e escura, de telhas pretas, deixou atrás os juazeiros, as pedras onde se jogavam cobras mortas, o carro de bois. As alpercatas dos pequenos batiam no chão branco e liso (p. 4).

[...] Repetia que era natural quando alguém lhe deu um empurrão, atirou-o contra o jatobá. A feira se desmanchava; escurecia; o homem da iluminação, trepando numa escada, acendia os lampiões. A estrela papaceia branqueou por cima da torre da igreja; o doutor juiz de direito foi brilhar na porta da farmácia; o cobrador da prefeitura passou coxeando, com talões de recibos debaixo do braço; a carroça de lixo rolou na praça recolhendo cascas de frutas; seu vigário saiu de casa e abriu o guardachuva por causa do sereno; Sinha Rita louceira retirou-se (p. 15).

[...] Fabiano meteu-se na vereda que ia desembocar na lagoa seca, torrada, coberta de catingueiras e capões de mato (p. 33) (RAMOS, 2003).

Figura 2 - Apresentação do resumo de Vidas Secas de Graciliano Ramos e leitura de alguns trechos.

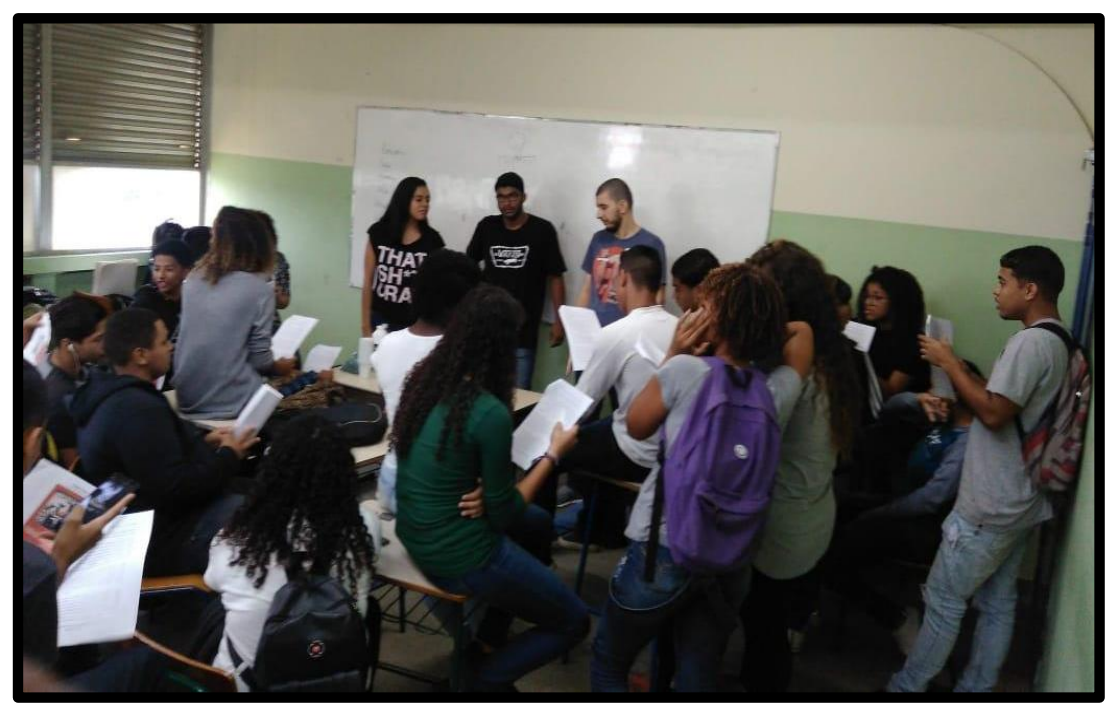

Fonte: Acervo dos autores (2019). 
Gabriela Sabatini Barros Sales Geografia, Literatura e Arte, v.2, n.2, p. 109-128, jul./dez.2020 Jeferson Rosa da Silva

DOI: 10.11606/issn.2594-9632.geoliterart.2020.168163

Maria Luiza Félix Marques Kede

Ana Claudia Ramos Sacramento

Conforme exposto, o intuito da oficina desenvolvida foi trabalhar o conceito de paisagem e a partir dos trechos do livro Vidas Secas buscou-se apresentar diferentes elementos inseridos nas paisagens. Com base na presente obra de Graciliano Ramos diferentes debates podem ser levantados, contudo considerando o propósito deste trabalho algumas temáticas e questões acerca do Nordeste não serão aprofundadas.

A partir dos trechos, as turmas conseguiram apreender de maneira geral a história contada no romance e imaginar as paisagens. Nesse momento, os alunos estimulados a lembrarem de outras paisagens nordestinas. Cabe ressaltar que um deles - nasceu no estado do Piauí e emigrou com a família para o município de São Gonçalo durante a adolescência - relatou de forma vivaz o contraste da paisagem associado ao regime de chuvas. Conforme suas palavras, "no período de chuva no Piauí a vegetação fica verde e, no período sem chuvas, as plantas vão murchando, perdendo sua beleza".

Souza (2008) alerta que existe um imaginário sobre o sertão. O autor levanta esse debate, a partir de produções cinematográficas em que os habitantes do sertão são tratados como pessoas ingênuas que habitam uma região árida e infértil e, por isso, migram para os grandes centros urbanos. Ele chama atenção para a necessidade de superar caricaturas e preconceitos, de modo a romper com as imagens estereotipadas e cristalizadas sobre o sertão e os nordestinos.

$\mathrm{Na}$ terceira etapa, os grupos prepararam as tintas de solos com cores variadas (Figura 3). Nesse momento buscou-se associar as amostras de solo coletadas no município de São Gonçalo às paisagens do local onde os alunos residem; abordando também características relacionadas ao solo e ao seu processo de formação. Desta forma, trabalhou-se a dimensão escalar discutida por Sacramento (2017). 
Gabriela Sabatini Barros Sales Geografia, Literatura e Arte, v.2, n.2, p. 109-128, jul./dez.2020 Jeferson Rosa da Silva

Maria Luiza Félix Marques Kede

Ana Claudia Ramos Sacramento

Figura 3 - Distribuição do material para a preparação das tintas com amostras de solos.

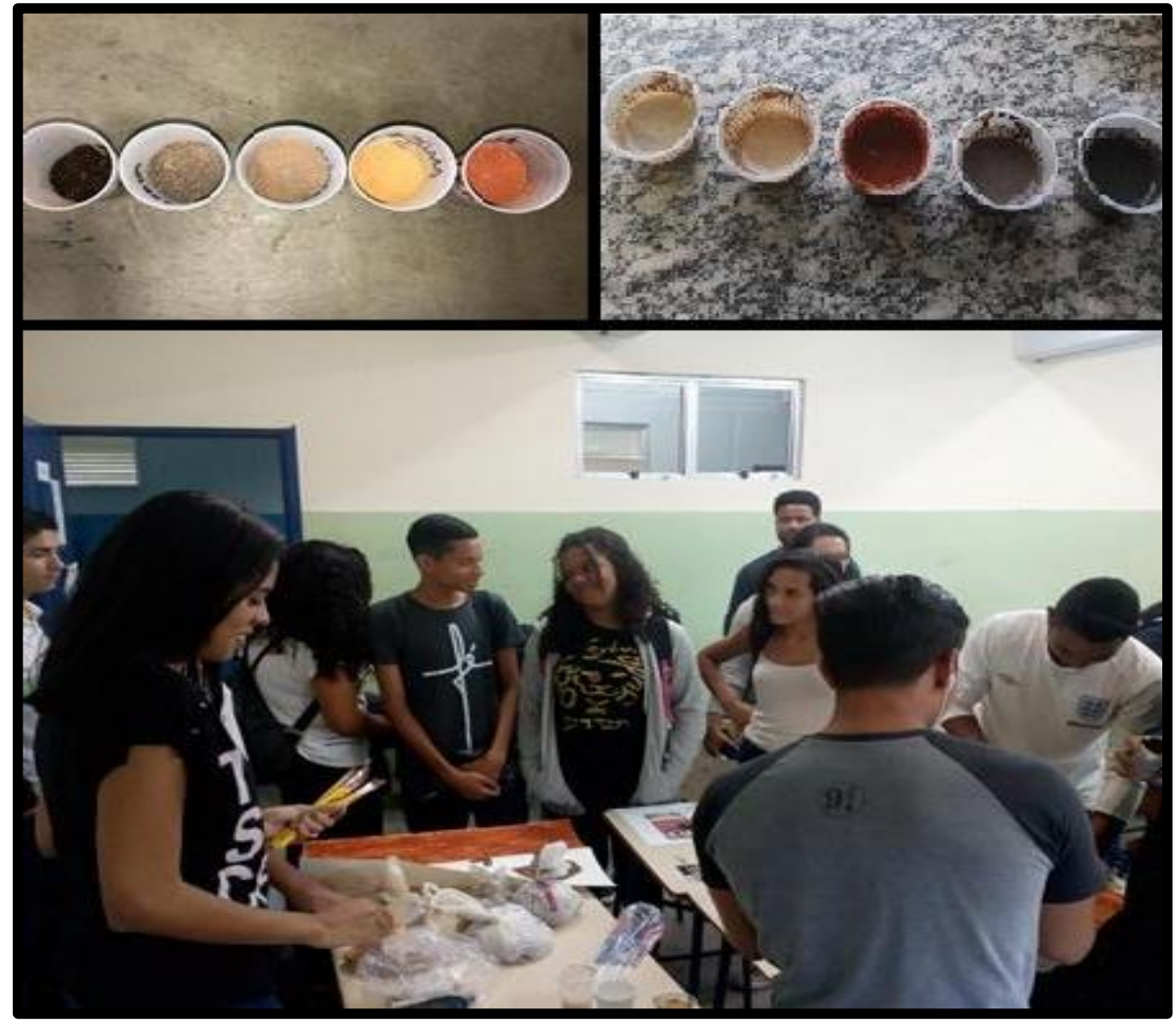

Fonte 3: Acervo dos autores (2019).

$\mathrm{Na}$ quarta etapa, os alunos apresentaram suas representações a respeito das paisagens, a partir de Vidas Secas e dos lugares onde vivem (Figura 4). Neste momento, foi importante resgatar também a dimensão do uso de diferentes materiais para desenvolver a atividade como o caso do Projeto Cores da Tinta (CARVALHO et al, 2009) no qual a produção de tintas fora ímpar para mostrar os diversos usos da terra e, no caso da pesquisa em aplicação, dos solos articulada com as paisagens desta obra literária. 
Gabriela Sabatini Barros Sales Geografia, Literatura e Arte, v.2, n.2, p. 109-128, jul./dez.2020

Jeferson Rosa da Silva

DOI: 10.11606/issn.2594-9632.geoliterart.2020.168163

Maria Luiza Félix Marques Kede

Ana Claudia Ramos Sacramento

Figura 4 - Apresentação das pinturas com tinta de solo preparadas em grupos pelos alunos retratando paisagens: (A) Caatinga, (B) A solidão do Nordestino, (C) preparação do grupo para a apresentação, (D) uma comunidade, (E) em destaque um vulcão.

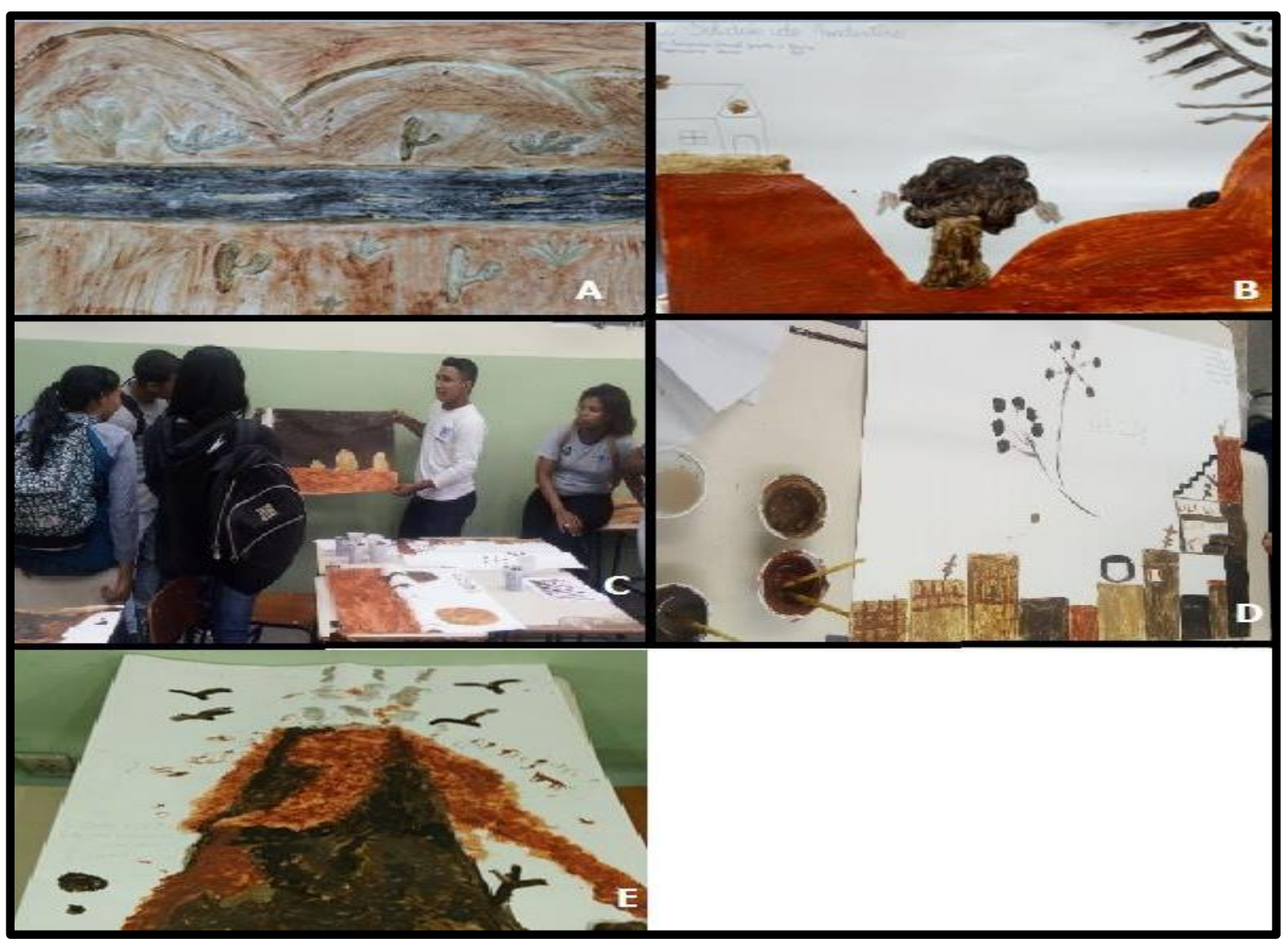

Fonte: Acervo dos autores (2019).

Desta maneira, a relação entre o Ensino da Geografia, Literatura, Paisagem e Solo de modo interdisciplinar permite construir o conhecimento dos estudantes, a partir de suas interpretações não só textuais, como também em imagens. Castellar e Vilhena (2010), assim como Sacramento (2017) chamam a atenção para a importância de se desenvolver atividades com imagens, como forma de se trabalhar a percepção dos estudantes. As imagens são representações que permitem compreender os significados e as interpretações dadas a elas e trabalhar se de fato o que se concebe é o real, é a ideia do conceito ou se é uma ideia limitada do conhecimento.

Em uma das apresentações, um grupo mostrou o semiárido nordestino com título "Caatinga", exibindo uma paisagem composta por morros, vegetação de cactos e uma estrada. Esta representação evidencia que os alunos compreenderam, possivelmente, as 
Gabriela Sabatini Barros Sales Geografia, Literatura e Arte, v.2, n.2, p. 109-128, jul./dez.2020

Jeferson Rosa da Silva

DOI: 10.11606/issn.2594-9632.geoliterart.2020.168163

Maria Luiza Félix Marques Kede

Ana Claudia Ramos Sacramento

dimensões do conceito de paisagem trabalhadas no início da aula, trazendo elementos naturais e as transformações ocasionadas pela ação humana, neste caso, retratada pela estrada presente na paisagem.

Em outro trabalho, um grupo representou uma casa na parte alta de um morro, uma árvore na parte baixa e o sol. O título dado foi “A solidão do nordestino". Neste momento, o aluno piauiense relatou sobre algumas dificuldades enfrentadas por sua família antes da vinda para o Estado do Rio de Janeiro e pela população que mora no interior, em especial, os problemas enfrentados pela falta d'água. Através da Literatura, o aluno pôde de algum modo relacionar as informações contidas no texto literário com o seu mundo real.

De todo modo, pode-se problematizar a representação criada pelo grupo e seu título, pois os alunos parecem ter homogeneizado a condição de vida dos nordestinos. Diante disso, cabe o questionamento: será que todos os nordestinos vivem solitariamente? Considerando as contribuições de Durval Muniz Albuquerque Jr (2011) convém destacar que existe um estereótipo acerca do Nordeste e dos nordestinos, de modo que é feita uma caracterização indiscriminada que apaga as multiplicidades e as diferenças individuais. Ressalta-se que o preconceito por origem geográfica no Brasil marca principalmente os nordestinos e se expressa, por exemplo, através dos estereótipos do "baiano" e do "paraíba". Além disso, os nordestinos são muitas vezes menosprezados e visto como o flagelado, o retirante, o migrante, o pau de arara, entre outros (ALBUQUERQUE JUNIOR, 2007).

Um grupo representou uma paisagem típica dos centros urbanos: as favelas. Este grupo não se restringiu a trabalhar as paisagens expostas no livro, mas trabalhou em cima das experiências obtidas no cotidiano. No município de São Gonçalo, assim como em muitos outros no Brasil, a desigualdade socioeconômica transformou-se em uma segregação nos usos do solo urbano e as favelas tornaram-se espaços com inúmeros problemas sociais (CAMPOS, 2012). Neste trabalho, os estudantes retrataram uma paisagem comum na localidade onde moram e deram um nome fictício de "G8 city". Criaram palavras para simbolizar pichações, representaram também os fogos e um jovem na laje brincando de soltar pipa.

Em outra apresentação, o grupo exibiu um vulcão. Explicaram que no bairro onde moram localiza-se "o maciço de Itaúna”, considerado um vulcão extinto há milhões de anos. Trata-se de uma paisagem bastante conhecida e retratada no município de São 
Gabriela Sabatini Barros Sales Geografia, Literatura e Arte, v.2, n.2, p. 109-128, jul./dez.2020

Jeferson Rosa da Silva

DOI: 10.11606/issn.2594-9632.geoliterart.2020.168163

Maria Luiza Félix Marques Kede

Ana Claudia Ramos Sacramento

Gonçalo. Motoki et al (2008) apresentam características geológicas e litológicas bem como expõe evidências vulcânicas presentes no maciço de Itaúna. Durante a atividade, os alunos do grupo também mencionaram a grande erupção do vulcão Vesúvio, no ano 79 d.C. que devastou Pompeia, uma cidade italiana. Observando a pintura, nota-se que os alunos foram criativos, extrapolando as paisagens apontadas nos trechos lidos e as conhecidas por eles no cotidiano, utilizando-se, assim, da criatividade.

A partir das imagens, pode-se trabalhar com diferentes possibilidades de análise sobre o que os estudantes entenderam dos fragmentos dos textos e o conceito de paisagem. De maneira interdisciplinar, partindo das representações trazidas por eles pôde ser discutida a concepção de paisagem e assim desconstruir algumas ideias e visões distorcidas sobre a população nordestina. Conclui-se como o trabalho interdisciplinar da Geografia com a Literatura promoveu o diálogo entre os diferentes campos do saber que ampliaram significativamente os conhecimentos de mundo de cada aluno participante da oficina.

\section{CONSIDERAÇÕES FINAIS}

A proposta de pensar de modo interdisciplinar a Geografia e a Literatura possibilitou dialogar com diferentes formas de expressão e de conhecimento, desconstruindo a maneira de organizar a aula do ponto de vista tradicional. O desenvolvimento da presente oficina contribuiu para que o conceito de paisagem fosse trabalhado de maneira diferenciada e interativa.

A proposta interdisciplinar mostrou-se, a princípio, desafiadora, porém bastante enriquecedora e prazerosa durante a realização da atividade. Segundo Paviani e Fontana (2009) e Sacramento (2017), a aprendizagem pelas oficinas possibilita que os estudantes possam trabalhar com a teoria e prática integradamente.

Para Castellar e Vilhena (2010), os estudantes precisam ser mobilizados a compreender o significado do conceito de paisagem na Geografia e isso ocorreu com a escolha da obra Vidas Secas e o uso das tintas de solo para pensar as paisagens. Os estudantes se mostraram atentos e foram muito participativos durante a oficina, contribuindo com seus comentários relacionados ao que foi apresentado por meio dos fragmentos do romance e com saberes e percepções da vida cotidiana. Eles buscaram 
Gabriela Sabatini Barros Sales Geografia, Literatura e Arte, v.2, n.2, p. 109-128, jul./dez.2020

Jeferson Rosa da Silva

DOI: 10.11606/issn.2594-9632.geoliterart.2020.168163

Maria Luiza Félix Marques Kede

Ana Claudia Ramos Sacramento

relacionar as ideias trabalhadas em sala, retratando por meio das suas representações as diferentes paisagens, explicando e justificando a escolha do grupo.

Cabe por fim destacar a importância de projetos de extensão como este que proporciona a aprendizagem, a troca de experiências e contribui para a formação dos alunos, dos professores e dos graduandos de Licenciatura. Sendo assim, é válido enfatizar que atividades dessa natureza precisam e devem ser estimuladas no espaço escolar. A partir desta oficina, observou-se o grande potencial do trabalho com diferentes disciplinas no processo ensino-aprendizagem.

\section{REFERÊNCIAS BIBLIOGRÁFICAS}

ALBUQUERQUE JÚNIOR, Durval Muniz de. Preconceito contra a origem geográfica e de lugar: as fronteiras da discórdia. São Paulo: Cortez, 2007.

ALBUQUERQUE JÚNIOR, Durval Muniz de. A invenção do Nordeste e outras artes. $5^{\mathrm{a}}$ ed. São Paulo: Cortez, 2011.

BOTOSO, Altamir. Opressores e oprimidos: uma leitura do romance Vidas secas, de Graciliano Ramos. Revista de Letras da Universidade Católica de Brasília. v. 6, n. 1/2, p. 49-66, dez. 2013. Disponível em: https://portalrevistas.ucb.br/index.php/RL/article/view/3807/3386. Acesso: 13 de set. 2020.

CAMPOS, Andrelino. Do quilombo à favela: a produção do "espaço criminalizado" no Rio de Janeiro. $5^{\text {a }}$ ed. Rio de Janeiro: Bertrand Brasil, 2012.

CARNEIRO, Joana Junqueira; DIAS, Rachel Quandt. Projeto cores da terra: potencial da tinta de solo para a extensão rural. In: V CONGRESSO LATINO AMERICANO DE AGROECOLOGIA. La Plata, Argentina, 2015, Anais p.1-4. Disponível em: http://sedici.unlp.edu.ar/bitstream/handle/10915/55007/Documento_completo.pdf?sequence =1. Acesso: 15 de mai. 2019.

CARVALHO, Rodrigo Janoni. Reflexões sobre Geografia e Literatura. ÁGORA Revisa Eletrônica, n. 19, p. 80-89, dez. $2014 . \quad$ Disponível em: http://agora.ceedo.com.br/ojs/index.php/AGORA_Revista_Eletronica/article/view/103.

Acesso: 12 de set. 2020

CARVALHO, Anôr Fiorini. et al. Cores da Terra: Fazendo tinta com terra! Viçosa, MG: Universidade Federal de Viçosa - Depto. de Solos Pró-Reitoria de Extensão e Cultura Programa TEIA Projeto Cores da Terra, 2009. Disponível em: https://biowit.files.wordpress.com/2010/11/cartilha-cores-da-terra-150dpi-modificada.pdf. Acesso: 10 de jun. 2020. 
Gabriela Sabatini Barros Sales Geografia, Literatura e Arte, v.2, n.2, p. 109-128, jul./dez.2020

Jeferson Rosa da Silva

DOI: 10.11606/issn.2594-9632.geoliterart.2020.168163

Maria Luiza Félix Marques Kede

Ana Claudia Ramos Sacramento

CASTELLAR, Sonia Maria Vanzella; VILHENA, Jerusa. Ensino de Geografia. $1^{a}$ ed. São Paulo: Cengage Learning, 2010.

CORRÊA, Roberto Lobato. A Paisagem e o Passado. Espaço Aberto, PPGG - UFRJ, v. 4, n.1, p. 37-46, 2014. Disponível em: https://revistas.ufrj.br/index.php/EspacoAberto/article/viewFile/2431/2077. Acesso: 20 de mai. 2014.

EXTRA, jornal: “Cedae inicia obras para construção da Estação de Tratamento de Esgoto em Alcântara”. Notícias 03/07/2014. Disponível em: https://extra.globo.com/noticias/rio/cedae-incia-obras-para-construcao-da-estacao-de tratamento-de-esgoto-em-alcantara-13117378.html. Acesso: 20 de set. 2018.

LIMA, Solange Terezinha de. Geografia e Literatura: alguns pontos sobre a percepção de paisagem. Geosul, Florianópolis, v.15, n.30, p 7-33, jul./dez. 2000. Disponível em: https://periodicos.ufsc.br/index.php/geosul/article/view/14190/13014. Acesso: 12 de mai. 2020.

MELO, Mychelle Priscila de; LIMA, João Donizete. Geografia e a literatura brasileira: percepção da paisagem nas obras de 'O Cortiço' e 'Sertão sem Fim'. Espaço em Revista, v. 20, n. 1, jan./jun., p. 100-113, 2018. Disponível em: https://www.revistas.ufg.br/espaco/article/view/53385. Acesso: 10 de jul. 2019.

MOTOKI, Akihisa et al. Rochas piroclásticas de preenchimentos de condutos subvulcânicos do Mendanha, Itaúna e Ilha de Cabo Frio, RJ, e seu processo de formação com base no modelo de implosão de conduto. Revista Geociências, UNESP, São Paulo, v.27, n. 4, p. 451-467, 2008 . Disponível em: https://www.revistageociencias.com.br/geociencias-arquivos/27_4/volume27_4.htm.

Acesso em: 15 de jun. 2019.

PAVIANI, Neires Maria Soldatelli; FONTANA, Niura Maria. Oficinas pedagógicas: relato de uma experiência. Revista Conjectura: Filosofia e educação. Caxias do Sul, v. 14, n. 2, mai/ago, p. 77-88, 2009. Disponível em: em: http://www.ucs.br/etc/revistas/index.php/conjectura/article/view/16/15. Acesso: 16 de jun. 2019

RAMOS, Graciliano. Vidas Secas. 89ª ed. Rio de Janeiro: Record, 2003.

SACRAMENTO, Ana Claudia Ramos. Ensino de Geografia e a Cidade de São Gonçalo. $1^{\mathrm{a}}$ ed. Seropédica: EDUR, 2017.

SACRAMENTO, Ana Claudia Ramos. Educação Geográfica: a didática, a mediação e a aprendizagem na construção dos conceitos. In: XIV COLÓQUIO IBÉRICO DE GEOGRAFIA 'A JANGADA DE PEDRA' GEOGRAFIAS IBERO-AFROAMERICANAS, 2014, Guimarães. 'A JANGADA DE PEDRA' Geografias Ibero-AfroAmericanas. Atas do Colóquio de Geografia. Guimarães: Associação Portuguesa de Geógrafos e Departamento de Geografia da Universidade do Minho, 2014, p. 182-187. 
Gabriela Sabatini Barros Sales Geografia, Literatura e Arte, v.2, n.2, p. 109-128, jul./dez.2020

Jeferson Rosa da Silva

DOI: 10.11606/issn.2594-9632.geoliterart.2020.168163

Maria Luiza Félix Marques Kede

Ana Claudia Ramos Sacramento

Disponível em: http://repositorium.sdum.uminho.pt/handle/1822/35660. Acesso em: 13 de mai. 2019.

SALES, Carla Monteiro. Paisagem fílmica e imaginário geográfico: representações do sertão nordestino no cinema da retomada. In: SUZUKI, Júlio César (Org); SILVA, Valéria Cristina Pereira (Org). Imaginário, Espaço e Cultura geografias poéticas e poéticas geografias. Porto Alegre: Imprensa Livre, 2016. p. 49-83. Disponível em: http://www.livrosabertos.sibi.usp.br/portaldelivrosUSP/catalog/download/110/94/4661?inline=1. Acesso: 13 de set de 2020 .

SANTOS, Milton. Metamorfose do Espaço Habitado: Fundamentos Teóricos Metodológicos da Geografia. 6 ${ }^{\text {a }}$ ed. São Paulo: Editora da Universidade de São Paulo, 2014.

SAUER, Carl. A morfologia da paisagem. In: CORREAA, Roberto Lobato; ROSENDAHL, Zeny. (orgs.). Paisagem, tempo e cultura. Rio de Janeiro: EdUERJ, p. 12-74, 1998 [1925].

SILVA, Igor Antônio.; BARBOSA, Tulio. O ensino de Geografia e a Literatura: uma contribuição estética. Caminhos de Geografia, Uberlândia, v. 15, n. 49, p. 80-89, mar/2014. Disponível em: http://www.seer.ufu.br/index.php/caminhosdegeografia/article/view/23358. Acesso: 10 de jun. 2019.

SILVA FILHO, Marcelo Nicomedes Reis; ARAÚJO, Geovana Oliveira; SILVA, Jeane Oliveira da. O estudo de paisagem nas aulas de Língua Portuguesa: uma proposta interdisciplinar. RELVA, Juara/MT/Brasil, v. 6, n. 1, p. 178-189, jan./jun. 2019. Disponível em: https://periodicos.unemat.br/index.php/relva/article/download/3775/3020. Acesso: 13 de set. 2020.

SOUZA, Gustavo. Mais do mesmo: o Nordeste e a confirmação de estereótipos na produção cinematográfica brasileira. Revista Interin, v. 6, n. 2, s/p, 2008. Disponível em: https://www.redalyc.org/pdf/5044/504450759008.pdf. Acesso: 20 de mai. 2019.

Recebido em 27/05/2020.

Aceito em 08/09/2020.

Publicado em 07/11/2020. 